\title{
Análise da produção científica sobre a inclusão no ensino superior brasileiro ${ }^{1}$
}

\section{Analysis of scientific production on the inclusion in Brazilian higher education}

\author{
Márcia Denise Pletsch* \\ Lúcia Pereira Leite**
}

\begin{abstract}
RESUMO
Desde os anos 1990, os direitos de pessoas com deficiência têm figurado nos debates nacionais e internacionais. Nesse contexto, os princípios da educação inclusiva têm sido incorporados nas diretrizes educacionais brasileiras, mas a sua extensão, desde a educação infantil até o ensino superior, foi reconhecida com maior destaque a partir de 2008, mediante a propagação da Política Nacional de Educação Especial na Perspectiva da Educação Inclusiva. Focando o ensino superior, este artigo parte da análise da temática tratada na produção científica disponível na base de dados Scientific Eletronic Library Online (SciELO-BRASIL). Os resultados mostraram que, apesar do avanço na produção de conhecimento sobre o tema, este ainda está muito aquém da demanda que cresce de forma acelerada, em grande medida, pelo incremento de políticas públicas que fomentam a participação de estudantes com deficiência. Tal aspecto coloca para as universidades o enfrentamento de uma série de questões para além das de infraestrutura, como de ordem pedagógica, social e atitudinal.

Palavras-chave: Políticas públicas de educação inclusiva. Ensino superior. Deficiência.
\end{abstract}

DOI: $10.1590 / 0104-4060.51042$

1 Artigo elaborado a partir da parceria estabelecida durante o desenvolvimento da pesquisa em rede "ACESSIBILIDADE NO ENSINO SUPERIOR: da análise das políticas públicas educacionais ao desenvolvimento de mídias instrumentais sobre deficiência e inclusão" (Processo $n^{\circ}$ 8.224/2012), financiado pelo Programa Observatório da Educação da Coordenação de Aperfeiçoamento de Pessoal de Nível Superior (OBEDUC/CAPES).

* Universidade Federal Rural do Rio de Janeiro (UFRRJ). Programa de Pós-Graduação em Educação. Seropédica, Rio de Janeiro, Brasil. BR 465. Km 07. CEP: 23890-00. E-mail: marciadenisepletsch@gmail.com

** Universidade Estadual Paulista (UNESP). Programa de Pós-Graduação em Psicologia e Desenvolvimento da Aprendizagem. Bauru, São Paulo, Brasil. Av. Eng. Luiz Edmundo Carrijo Coube, nº 14-01. Vargem Limpa. CEP: 17033-360. E-mail: lucialeite@fc.unesp.br 


\begin{abstract}
Since the 90's, the rights of people with disabilities have been part of national and international debates. In this context, the principles of inclusive education have been incorporated into Brazilian educational guidelines, but their extension from early childhood education to higher education has been most notably recognized from 2008 onwards, through the propagation of the National Policy of Special Education in the inclusive education perspective. Focusing on higher education, this paper starts from the analysis of the thematic as treated in the scientific production available in the Scientific Electronic Library Online database (SciELO-BRAZIL). The results showed that, despite the advances in the production of knowledge on the subject, it still falls short of the demand, which grows at an accelerated rate, largely due to the development of public policies that foster the participation of students with disabilities. This aspect puts universities facing a number of issues beyond infrastructure, such as the ones of pedagogical, social and attitudinal order.
\end{abstract}

Keywords: Public policies of inclusive education. Higher education. Deficiency.

Desde os anos 1990, os direitos sociais e educacionais de pessoas com deficiência têm figurado nos debates nacionais e internacionais. Nesse contexto, o ensino superior tem sido cada vez mais reconhecido como agente impulsionador de desenvolvimento das sociedades, sobretudo, após a Declaração Mundial sobre ensino superior de 1998, que o reconhece como um dos pilares fundamentais dos direitos humanos, da democracia, do desenvolvimento sustentável e da paz. Essa Declaração sinaliza que, se de um lado, a universidade é o locus da produção do conhecimento das diferentes áreas do saber, por outro, deve ser também o espaço da pluralidade, da diversidade e do respeito às diferenças, garantindo o acesso a todos que desejarem realizá-lo (SANTOS et al., 2015).

Para atender a essas premissas, os princípios da educação inclusiva têm sido incorporados nas diretrizes educacionais de diferentes países. No Brasil, a extensão da proposta de inclusão, desde a educação infantil até o ensino superior, foi reconhecida a partir de 2008, mediante a promulgação da Política Nacional de Educação Especial na Perspectiva da Educação Inclusiva. O texto normativo segue as orientações da Convenção das Nações Unidas sobre os Direitos das Pessoas com Deficiência (BRASIL, 2011), realizada em 2007, nos Estados Unidos, a qual foi incorporada como Emenda Constitucional no Brasil pelo Decreto $n^{\circ}$ 6.949/2009, da Casa Civil.

Nesse período cresceu significativamente o ingresso de discentes público-alvo da Educação Especial - pessoas com deficiência física, intelectual, sen- 
sorial, transtornos globais do desenvolvimento e altas habilidades - no ensino superior nacional, sobretudo, em decorrência da criação de novas instituições de ensino superior (IES) e da implantação de ações governamentais que estimulassem o acesso de minorias sociais, como o Programa Universidade para Todos (PROUNI), do Programa de Financiamento Estudantil (FIES). Tais inciativas repercutiram positivamente nas matrículas nesse nível de ensino, pois, de acordo com os dados do Instituto Nacional de Estudos e Pesquisas Nacionais Anísio Teixeira (INEP), tivemos um crescimento de $85,35 \%$ de matrículas entre os anos de 2004 a 2014. No caso do público-alvo mencionado, os dados mostram que o aumento foi expressivo, algo em torno de 520\%, atingindo 33.377 matrículas. Todavia, esse crescimento ainda está longe do ideal, pois apenas $0,37 \%$ da participação no ensino superior se refere ao montante de estudantes que se encontram nessa condição. Aliás, cabe dizer que ainda enfrentamos enormes desafios para garantir o acesso e a permanência dessa população em todos os níveis de ensino.

Vale mencionar que, numa análise mais apurada dos dados censitários do Instituto Brasileiro de Geografia e Estatística (IBGE), segundo a Cartilha do Censo 2010 (BRASIL, 2012), na época 8,3\% da população brasileira apresentavam pelo menos um tipo de deficiência severa, sendo: $3,46 \%$ com deficiência visual severa, $1,12 \%$ com deficiência auditiva severa, $2,33 \%$ com deficiência motora severa, $1,4 \%$ com deficiência mental ou intelectual. Isto representava, em termos absolutos, 15.830 .813 pessoas. Desse total $14,15 \%$ possuem o fundamental completo ou médio incompleto; $17,67 \%$ possuem o médio completo ou superior incompleto e cerca de $61 \%$ não têm qualquer instrução ou têm apenas o fundamental completo. $\mathrm{O}$ contingente de pessoas identificadas com deficiência severa foi calculado pela soma das respostas positivas às perguntas: "tem grande dificuldade" e "não consegue de modo algum" (BRASIL, 2012).

Esses números indicam tanto os desafios a serem enfrentados pelas IES como a necessidade da academia em se debruçar na investigação sobre a temática. Desse modo, pensando em discutir os avanços na área, propomos, neste artigo, retratar o estado da arte da produção científica que envolvem a participação de pessoas público-alvo da Educação Especial no ensino superior.

Em termos procedimentais, propomos uma discussão qualitativa a partir da varredura da literatura a respeito. Como campo investigativo, delimitamos o levantamento das produções científicas publicadas na base de dados Scientific Eletronic Library Online (SciELO-Brasil). Entendemos que pesquisas dessa natureza fornecem um panorama da produção científica sobre o tema e apontam as tendências e demandas de investigação. Em outros termos, de caráter bibliográfico, o estado da arte na concepção de Ferreira (2002), Nascimento, Cruz e Braun (2017) se configura como um recurso metodológico que tenta 
responder aspectos e contextos pesquisados em diferentes épocas e localidades. Dessa forma, assume "um perfil próximo a um inventário com layout de cunho descritivo" (NASCIMENTO; CRUZ; BRAUN, 2017, p. 3).

Para constituir o corpus analítico, focamos as produções publicadas no período de 2008 a 2016. Esse recorte temporal se fundamenta na intenção de coadunar com a data da publicação da Política Nacional de Educação Especial na Perspectiva da Educação Inclusiva. Para localizar a produção, utilizamos as seguintes expressões como descritores associados de busca: inclusão no ensino superior, acessibilidade no ensino superior, pessoas com deficiência no ensino superior, políticas públicas de inclusão no ensino superior. Nesse intervalo foram localizados 20 artigos que abordavam a temática da inclusão do ensino superior. A seguir, o Quadro 1 ilustra a sua catalogação.

\section{QUADRO 1 - ARTIGOS CATALOGADOS ENVOLVENDO A TEMÁTICA IN- CLUSÃO NO ENSINO SUPERIOR}

\begin{tabular}{|l|c|l|}
\hline \multicolumn{1}{|c|}{ Autor (es) } & Ano & \multicolumn{1}{|c|}{ Titulo } \\
\hline $\begin{array}{l}\text { Ana Cristina Guarinelo, Ana Paula } \\
\text { Berberian, Ana Paula de O. Santana, } \\
\text { Kyrlian B. Bortolozzi, Simone Shem- } \\
\text { berg e Luciana C. Figueiredo }\end{array}$ & 2009 & $\begin{array}{l}\text { Surdez e letramento: pesquisa com surdos uni- } \\
\text { versitários de Curitiba e Florianópolis }\end{array}$ \\
\hline $\begin{array}{l}\text { José Ildon G. da Cruz e Tárcia R. da } \\
\text { Silveira Dias }\end{array}$ & 2009 & $\begin{array}{l}\text { Trajetória escolar do surdo no ensino superior: } \\
\text { condições e possibilidades }\end{array}$ \\
\hline Monique Franco & 2009 & $\begin{array}{l}\text { Educação superior bilíngue para surdos: o } \\
\text { sentido da política inclusiva como espaço da } \\
\text { liberdade: primeiras aproximações }\end{array}$ \\
\hline $\begin{array}{l}\text { Michele X. dos Reis, Daniela A. Eu- } \\
\text { frásio e Fernanda V. Mafra Bazon }\end{array}$ & 2010 & $\begin{array}{l}\text { A formação do professor para o ensino supe- } \\
\text { rior: prática docente com alunos com deficiên- } \\
\text { cia visual }\end{array}$ \\
\hline $\begin{array}{l}\text { Cláudia A. Bisol, Carla B. Valentini, } \\
\text { Janaína L. Simioni e Jaqueline Zan- } \\
\text { chin }\end{array}$ & 2010 & $\begin{array}{l}\text { Estudantes surdos no ensino superior: refle- } \\
\text { xões sobre a inclusão }\end{array}$ \\
\hline $\begin{array}{l}\text { Inajara M. Siqueira e Carla da Silva } \\
\text { Santana }\end{array}$ & 2010 & $\begin{array}{l}\text { Propostas de acessibilidade para a inclusão de } \\
\text { pessoas com deficiência no ensino superior }\end{array}$ \\
\hline $\begin{array}{l}\text { Laura C. Moreira, Maria A. Bolsanello } \\
\text { e Rosângela G. Seger }\end{array}$ & 2011 & $\begin{array}{l}\text { Ingresso e permanência na universidade: alu- } \\
\text { nos com deficiências em foco }\end{array}$ \\
\hline $\begin{array}{l}\text { Francilene Jane Rodrigues Pereira, } \\
\text { Sérgio Ribeiro dos Santos e César Ca- } \\
\text { valcanti da Silva }\end{array}$ & 2011 & $\begin{array}{l}\text { Política de formação inclusiva: percepção de } \\
\text { gestores sobre processo de mudanças em Insti- } \\
\text { tuições de ensino superior }\end{array}$ \\
\hline $\begin{array}{l}\text { Cristina Broglia Feitosa de Lacerda e } \\
\text { Taís Margutti do Amaral Gurgel }\end{array}$ & 2011 & $\begin{array}{l}\text { Perfil de tradutores-intérpretes de Libras } \\
\text { (TILS) que atuam no ensino superior no Brasil }\end{array}$ \\
\hline $\begin{array}{l}\text { Ani Martins Silva, Raquel Cymrot e } \\
\text { Maria Eloisa Famá D’Antino }\end{array}$ & 2012 & $\begin{array}{l}\text { Demandas de docentes do ensino superior para } \\
\text { a formação de alunos com deficiência }\end{array}$ \\
\hline
\end{tabular}

(continua) 
(conclusão)

\begin{tabular}{|l|c|l|}
\hline $\begin{array}{l}\text { Emerson R. Duarte, Carla B. da Silva } \\
\text { Rafael, Juliana Fernandes Filgueiras, } \\
\text { Clara M. Neves e Maria Elisa Caputo } \\
\text { Ferreira }\end{array}$ & 2013 & $\begin{array}{l}\text { Estudo de caso sobre a inclusão de alunos com } \\
\text { deficiência no ensino superior }\end{array}$ \\
\hline $\begin{array}{l}\text { Fabiane S.C. Cianca e Maria Cristina } \\
\text { Marquezine }\end{array}$ & 2014 & $\begin{array}{l}\text { A percepção dos coordenadores de licenciatu- } \\
\text { ras da UEL sobre altas habilidades/superdota- } \\
\text { ção }\end{array}$ \\
\hline $\begin{array}{l}\text { Mário Luiz Ferrari Nunes e Marcos } \\
\text { Garcia Neira }\end{array}$ & 2014 & $\begin{array}{l}\text { Processos de inclusão excludente presentes no } \\
\text { ensino superior privado }\end{array}$ \\
\hline $\begin{array}{l}\text { Sabrina Fernandes de Castro e Maria } \\
\text { Amélia Almeida }\end{array}$ & 2014 & $\begin{array}{l}\text { Ingresso e permanência de alunos com defi- } \\
\text { ciência em universidades públicas brasileiras }\end{array}$ \\
\hline $\begin{array}{l}\text { Diléia A. Martins, Lúcia Pereira Leite } \\
\text { e Cristina Broglia }\end{array}$ & 2015 & $\begin{array}{l}\text { Políticas públicas para acesso de pessoas com } \\
\text { deficiência ao ensino superior brasileiro: uma } \\
\text { análise de indicadores educacionais }\end{array}$ \\
\hline $\begin{array}{l}\text { Woquiton Lima Fernandes e Carolina } \\
\text { Severino Lopes da Costa }\end{array}$ & 2015 & $\begin{array}{l}\text { Possibilidades da tutoria de pares para estu- } \\
\text { dantes com Deficiência Visual no Ensino Téc- } \\
\text { nico e Superior }\end{array}$ \\
\hline $\begin{array}{l}\text { Ronaldo Q. de Oliveira, Silvana M. } \\
\text { B. de Oliveira, Natália A. de Oliveira, } \\
\text { Maria Cristina S. F. Trezza, Iara B. Ra- } \\
\text { mos e Daniel A. Freitas }\end{array}$ & 2016 & $\begin{array}{l}\text { A inclusão de pessoas com necessidades espe- } \\
\text { ciais no ensino superior }\end{array}$ \\
\hline $\begin{array}{l}\text { Aline Lima, Adriana P. dos S. Mar- } \\
\text { ques, Angélica H. dos S. Lima e Ga- } \\
\text { briela C. Lobato }\end{array}$ & 2016 & $\begin{array}{l}\text { Inclusão no ensino superior: uma proposta de } \\
\text { ação em Psicologia Escolar }\end{array}$ \\
\hline $\begin{array}{l}\text { Ana Paula C. Ciantelli e Lúcia P. Leite } \\
\text { Frederico Fumes }\end{array}$ & 2016 & $\begin{array}{l}\text { Ações exercidas pelos Núcleos de Acessibili- } \\
\text { dade nas Universidades Federais Brasileiras }\end{array}$ \\
\hline $\begin{array}{l}\text { David dos S. Calheiros e Neiza de L. } \\
\text { fraclusão de universitários com deficiência } \\
\text { em cursos de Educação Física na cidade de } \\
\text { Maceió/AL }\end{array}$ \\
\hline
\end{tabular}

FONTE: elaborado pelas autoras.

A partir da leitura integral, um dos artigos foi excluído da amostra por não apresentar vinculação com a especificidade da temática investigada. Desse modo, a amostra analisada contou com 19 artigos que foram organizados em um conjunto de três categorias, a saber: a) Revisão de Políticas, estudos e experiências de inclusão no ensino superior, com oito produções; b) Formação e suportes pedagógicos oferecidos para a inclusão de pessoas com deficiência no ensino superior, com cinco produções; c) Mapeamento e trajetórias de pessoas com deficiência no ensino superior, com seis produções. O Quadro 2, a seguir, sintetiza a seleção dos artigos por categoria. 
QUADRO 2 - RELAÇÃO DE CATEGORIAS ELENCADAS A PARTIR DA ANÁLISE DOS ARTIGOS

\begin{tabular}{|l|l|}
\hline \multicolumn{1}{|c|}{ Categorias } & \multicolumn{1}{|c|}{ Autores e ano da publicação } \\
\hline $\begin{array}{l}\text { Revisão de políticas, estudos e experiências de } \\
\text { inclusão no ensino superior }\end{array}$ & $\begin{array}{l}\text { Franco (2009); Siqueira e Santana (2010); } \\
\text { Lacerda e Gurgel (2011); Moreira, Bolsanello } \\
\text { e Seger (2011); Pereira, Santos e Silva (2011); } \\
\text { Silva, Cymrot e D’Antino (2012); Martins, } \\
\text { Leite e Broglia (2015); Oliveira et al. (2016) }\end{array}$ \\
\hline $\begin{array}{l}\text { Formação e suportes pedagógicos oferecidos } \\
\text { para a inclusão de pessoas com deficiência no } \\
\text { ensino superior }\end{array}$ & $\begin{array}{l}\text { Reis et al. (2010); Castro e Almeida (2014); } \\
\text { Fernandes e Costa (2015); Ciantelli e Leite } \\
\text { (2016); Lima, Marques e Lima (2016) }\end{array}$ \\
\hline $\begin{array}{l}\text { Mapeamento e trajetórias de pessoas com } \\
\text { deficiência no ensino superior }\end{array}$ & $\begin{array}{l}\text { Guarinello et al. (2009); Cruz e Dias (2009); } \\
\text { Bisol et al. (2010); Cianca e Marquezine } \\
\text { (2014); Duarte et al. (2013); Calheiros e } \\
\text { Fumes (2016) }\end{array}$ \\
\hline
\end{tabular}

FONTE: elaborado pelas autoras.

Com base na organização dessas categorias, propomos a análise dos artigos em diálogo com a literatura especializada na área.

\section{Revisão de políticas, estudos e experiências de inclusão no ensino superior}

Dando início, temos o texto de Franco (2009), que discute o ensino superior bilíngue a partir da experiência em curso do Instituto Nacional de Educação de Surdos (INES), na implantação do curso de Pedagogia Bilíngue. O artigo apresenta uma discussão sobre o Decreto $n^{0} 5.626 / 2005$, que regulamenta a Lei $\mathrm{n}^{\circ} 10.436 / 2002$, para em seguida refletir sobre o sentido da política de educação inclusiva no contexto do bilinguismo. O Curso Normal Superior Bilíngue, formado por alunos surdos e não surdos, iniciou em 2006. No mesmo ano, com a homologação das Diretrizes Nacionais para Cursos de Pedagogia, ele foi transformado em curso de Pedagogia Bilíngue. A experiência inédita, ainda hoje no Brasil, tem a Libras como língua de instrução e o Português como disciplina obrigatória.

A experiência tem revelado as contradições e desafios inerentes a implementação de propostas inovadoras dessa natureza. $\mathrm{O}$ artigo sinaliza para duas questões importantes: a primeira, segundo a autora, o curso não deve ser considerado bilíngue, uma vez que a primeira língua tem sido utilizada de forma precária por ouvintes. Para ela, essa precariedade não se resolve apenas 
por meio de intérpretes. Isto é, um curso dessa natureza não pode prescindir de questões teóricas e práticas que identifiquem processos específicos da educação de surdos no ensino superior. O segundo aspecto se refere a necessidade constante de revisão do Projeto Político Pedagógico do curso para atender as demandas que são comuns em propostas consideradas inovadoras. A autora defende, ainda, que estudos sobre os perfis docentes para as vagas de concurso estejam de acordo com as demandas do curso. Ao finalizar o texto, indica que o Curso Normal Superior Bilíngue pode ser uma possibilidade de construção de uma política cultural bilíngue para o país. A nosso ver, além das questões colocadas no artigo, o curso em questão pode contribuir, sobremaneira, com a formação de professores para o ensino bilíngue de surdos.

A garantia de acesso no ensino superior foi abordada também por Siqueira e Santana (2010), que objetivaram descrever, a partir de pesquisa documental, ações contidas nas propostas de onze instituições de ensino superior contempladas pelo "Projeto Incluir/MEC-Acessibilidade no Ensino Superior", no período de 2005 a 2008. Os resultados foram organizados em três categorias, elaboradas a partir dos fatores ambientais propostas pela Classificação Internacional de Funcionalidade, Incapacidade e Saúde (CIF) da Organização Mundial de Saúde (OMS), o que permitiu articular a interdependência entre atitudes sociais, produtos e tecnologias voltadas para a otimização da funcionalidade das pessoas e as políticas de inclusão. De maneira geral, os resultados indicaram que os projetos contemplados focalizaram ações no âmbito da promoção da acessibilidade física da pessoa com deficiência, garantindo, assim, o acesso aos ambientes das universidades e a participação de práticas esportivas. Efetivaram ainda ações voltadas para o debate junto aos técnicos administrativos, docentes e alunos sobre inclusão, com o objetivo de rever estigmas e preconceitos presentes na comunidade acadêmica em relação à participação de pessoas com deficiência no ensino superior. Nessa direção, os projetos acabaram propondo articulação com diferentes instâncias institucionais de forma a contribuir com o debate sobre o ensino e a elaboração de mecanismos de identificação das necessidades específicas dos sujeitos frente aos processos de ensino e aprendizagem. A este respeito, contribuíram para introduzir modificações curriculares e serviços de apoio para o atendimento às necessidades educacionais especiais. Além dessas ações, a análise dos projetos evidenciou a realização de parcerias entre a educação básica e o ensino superior com o objetivo de promover ações conjuntas para fomentar a pesquisa, o ensino e as atividades de extensão na região.

O perfil de tradutores-intérpretes de Libras (TILS) que atuam no ensino superior no Brasil foi analisado por Lacerda e Gurgel (2011). Foram realizadas, com apoio de ferramentas disponíveis na internet, 37 entrevistas com TILS que atuam no ensino superior em instituições públicas ou privadas de diferentes 
estados das cinco regiões brasileiras. Entre outros aspectos, os dados indicaram que, dos 37 entrevistados, grande parte, ou seja, 70\% eram do sexo feminino, a faixa etária mais recorrente foi de 21 a 35 anos de idade (61\%). Os estados com maior atuação de TILS foram os da Região Sudeste (São Paulo e Minas Gerais), sendo que, a maioria exercia sua função em instituições privadas.

Em relação à formação dos TILS, a pesquisa mostrou que $64 \%$ possuíam ensino superior em diferentes cursos, mas não necessariamente atuavam na área em que tiveram formação. Os dados indicaram também que $23 \%$ estavam cursando o ensino superior e que 13\% não tinham experiência em atuar nesse nível de ensino. Tais dados mostraram uma formação heterogênea dos profissionais TILS que atuavam no ensino superior. Muitos, inclusive, aprenderam Libras por serem filhos de pais surdos e assim iniciaram a atuação como intérpretes de sinais em empresas e outros espaços sociais que não tinham qualquer relação com a educação. Mas, por saberem Libras, foram indicados para atuar no ensino superior por pessoas que já conheciam o seu trabalho. Apenas um dos entrevistados foi selecionado por concurso público. Os autores do artigo evidenciaram a necessidade de oferecer uma formação qualificada para a atuação como TILS. Segundo Lacerda e Gurgel, fazem-se necessários conhecimentos linguísticos em Libras e em Português para atuar como TILS, além do contato com a comunidade surda. Igualmente, entendem que "a interpretação requer conhecimentos de mundo, escolhas léxicas e de sentido que precisam ser trabalhadas para que o intérprete atue adequadamente favorecendo a aprendizagem do estudante surdo" (2011, p. 495).

A inclusão de pessoas com deficiência, na educação básica e no ensino superior, foi discutida por Moreira, Bolsanello e Seger (2011) ao abordarem aspectos sobre o ingresso e a permanência desses sujeitos no ensino superior. Para tal, apresentaram e discutiram a trajetória da Universidade Federal do Paraná (UFPR), evidenciando as diretrizes legais e as principais ações desenvolvidas no contexto desta instituição a partir da realização de entrevistas com sete alunos (três com cegueira, dois com deficiência física, um com deficiência múltipla e um com surdez).

Os dados coletados, entre outras questões, mostraram que a UFPR, desde os anos de 1990, vem executando um conjunto de ações para favorecer o acesso e o apoio pedagógico de estudantes com deficiências em seus cursos de graduação. A análise sinaliza as vivências e as estratégias encontradas pelos discentes para permanecer na universidade. Um dos principais destaques dados pelos discentes se refere ao uso de adaptações e recursos utilizados pelos professores nas aulas, como, por exemplo, a utilização de gravador e do computador. Destacaram a atitude positiva dos docentes que "não estão alheios à inclusão dos alunos com deficiências na Universidade" (MOREIRA; BOLSANELLO; SEGER, 2011, 
p. 138), diferente de resultados encontrados em pesquisas anteriores. Um dos principais aspectos negativos evidenciados nas entrevistas se refere à falta de acessibilidade arquitetônica nas dependências da instituição.

Em direção semelhante, a pesquisa de Pereira, Santos e Silva (2011) discutiu a inclusão no ensino superior a partir da percepção de quatro gestores de cursos de Enfermagem de instituições de ensino superior, localizadas em João Pessoa, na Paraíba. A análise das entrevistas evidenciou que os gestores se preocupam com as demandas colocadas pela política de inclusão. Dentre as modificações necessárias sinalizaram para a acessibilidade dos espaços físicos. Evidenciaram a importância de modificações nas metodologias de ensino aplicadas na formação profissional para atender as especificidades de estudantes com deficiências. Para finalizar, indicaram que a qualidade do ensino nas instituições de ensino superior "deve ser direcionada no intuito de acolher sujeitos com diferenças de gênero, cultura, religião, entre outras" (PEREIRA; SANTOS; SILVA, 2011, p. 715). Essa reflexão mostra que os gestores entendem a proposta de inclusão para além da matrícula de pessoas com deficiência, mas de forma a acolher a diversidade dos sujeitos que acessam ao ensino superior.

Silva, Cymrot e D'Antino (2012), ao tematizarem a inclusão no ensino superior, focaram a análise e o mapeamento das demandas didático-pedagógicas do corpo docente de uma universidade particular de São Paulo. A coleta de dados se deu por questionários que foram tabulados e analisados estatisticamente e descritivamente. A amostra foi composta de 752 professores, sendo 275 do sexo feminino e 465 do sexo masculino, 12 não informaram o sexo. A maioria dos professores participantes era formada na área de humanidades (52,5\%), seguida da área de exatas $(29,7 \%)$, de saúde $(10,3 \%)$ e biológicas (4\%). Parte significativa dos docentes (532) afirmou ter experiência com alunos com deficiência no ensino superior, sendo que a maior parte ressaltou a atuação junto a alunos com deficiência física. Nesse sentido, as concepções docentes revelaram, assim como em outros estudos apresentados neste artigo, que uma das principais demandas para garantir a inclusão de alunos com deficiência se refere a eliminação de barreiras arquitetônicas, adaptação de mobiliário e de materiais didático-pedagógicos. Em medida semelhante, foram mencionadas adaptações nos procedimentos de avaliação e de ensino, assim como a eliminação de barreiras interpessoais relacionadas a atitudes negativas em relação às pessoas com deficiência.

A pesquisa ilustrou as demandas expressas pelos docentes no que diz respeito a inclusão de estudantes com deficiência auditiva (termo usado pelos autores). Para eles é fundamental a presença do intérprete de Libras, uso de recursos pedagógicos no atendimento à especificidade linguística dos surdos e a realização de complementação da avaliação da aprendizagem, sobretudo, 
no caso de avaliações envolvendo textos escritos. Referente aos estudantes com deficiência visual (cegos ou com baixa visão), as concepções docentes revelaram ser importante o uso da máquina Braile, impressora, sistema de voz e scanner, gravador, lupas e réguas de leitura, software de ampliação de tela e acervo bibliográfico em áudio e dos conteúdos básicos em Braile. Por último, as concepções docentes revelaram, ainda, ser importante garantir ações de apoio ao professor por meio de cursos de capacitação, criação de núcleos de suporte especializado permanente aos docentes, o qual deverá atuar também em campanhas que contribuam para conscientizar a comunidade sobre educação inclusiva e na eliminação de preconceitos em relação às pessoas com deficiência.

Na revisão da literatura de produção científica sobre a educação inclusiva no ensino superior, tem-se o estudo de Oliveira et al. (2016). O texto informa que a varredura se deu em bases de dados eletrônicos, como Lilacs, SciELO, Cochrane, Medline e PubMed, no intervalo de 2005 a 2014, pelo uso de descritores controlados e não controlados. Após o refinamento do levantamento inicial, a amostra analisada foi de 16 artigos. No texto, há um detalhamento das referidas produções, indicando ano, procedência e formação acadêmica dos autores e delineamento adotado. $\mathrm{O}$ interessante texto categoriza em temas o material encontrado: padrões normativos e organizacionais das IES como determinantes atitudinais; comparação entre legislação, discurso político e prática social; perfil e formação dos docentes do ensino superior; condicionantes do ambiente físico; fisiopatologia das deficiências como barreira. Os dois primeiros temas foram recorrentes em mais da metade da amostra analisada.

Os autores comentam que, na varredura inicial dos materiais, se percebeu que grande parte dos estudos encontrados nas bases consultadas tratava a deficiência mais como uma demanda da área da saúde, num viés mais descontextualizado das instâncias sociais. Isso reflete que a adoção de um modelo biológico ainda está presente na comunidade científica. Ainda concluíram que "[...] o tema da educação inclusiva é mais estudado em relação às crianças, ou quando as atenções dos estudiosos são voltadas a pessoas adultas e crianças com necessidades especiais, envolve mais a assistência em saúde e não a educação inclusiva no ensino superior" (OLIVEIRA et al., 2016, p. 312).

Até a atualidade, o número de matrículas de estudantes referidos com público-alvo da Educação Especial se configura num interessante objeto de estudo. Tal fato é destacado no levantamento apresentado por Martins, Leite e Broglia (2015) numa pesquisa que procurou analisar as políticas relativas às matrículas da Educação Especial no ensino superior brasileiro nos indicadores educacionais. Os documentos analisados se concentraram nos resumos técnicos e planilhas do Censo da Educação Superior, referente ao período de 2000 a 2011, além de dados referentes ao Programa Incluir (2005 a 2011). Após ampla 
revisão das normativas que orientam a educação inclusiva no país e dos dados divulgados pelo INEP, as autoras comentam a evolução do número de matrículas de estudantes com deficiência em cursos de graduação presencial e a distância na última década, principalmente nas instituições públicas. Relatam, em igual medida, as políticas públicas que amparam ações diferenciadas no atendimento às necessidades educacionais especiais, apresentadas por esse público no contato com as propostas curriculares. Por fim destacam as demandas levantadas nos dados censitários de 2011, em termos de recursos de acessibilidade, disponibilizados pelas instituições de ensino superior no atendimento aos estudantes com deficiência visual, física ou auditiva.

\section{Formação e suportes pedagógicos oferecidos para a inclusão de pessoas com deficiência no ensino superior}

A formação de professores para atuar no ensino superior foi destaque no artigo de Reis, Eufrásio e Bazon (2010). O foco do texto foi discutir, a partir de uma pesquisa qualitativa que adotou como procedimento de coleta de dados a entrevista semiestruturada, a prática docente com estudantes com deficiência visual. Tal investigação se deu a partir da análise da formação de cinco professores universitários formados na licenciatura do curso de Ciências Biológicas, em uma universidade localizada no Sul de Minas Gerais. Por meio das categorias de análise, foram levantadas convergências nos discursos dos sujeitos, os quais evidenciaram, entre outros aspectos, as concepções dos docentes sobre a deficiência visual e a inclusão, a formação inicial e a continuada, assim como a experiência profissional e a utilização de material didático para as aulas com pessoas com deficiência visual.

Em relação à formação inicial, os entrevistados evidenciaram que não tiveram conteúdo ou disciplinas sobre o tema durante a sua graduação. Igualmente, sinalizaram que não tiveram nenhum contato com estudantes com deficiência visual em suas trajetórias acadêmicas. A maioria informou que não teve qualquer formação continuada envolvendo a temática, mas mostrou disposição para participar de formações nessa direção. Sobre o material didático ficou evidenciado sua necessidade para atender as especificidades dos discentes durante as aulas, inclusive como aspecto fundamental para garantir a inclusão. No entanto, grande parte dos docentes não sabia como construir/desenvolver esses recursos. Apesar disso, de maneira geral, o estudo evidenciou que as concepções dos docentes sobre a deficiência visual e a inclusão continuam mostrando o desconhecimento 
sobre os temas. Nessa direção, assim como os autores, entendemos que fomentar a formação continuada para professores do ensino superior é uma importante ferramenta para efetivar plenamente a inclusão de pessoas com deficiência nesse nível educacional.

A possibilidade de cursar níveis mais elevados de ensino tem se mostrado uma ação real no país nos últimos anos. Nesse direcionamento, práticas que auxiliem estudantes com deficiência se mostram viáveis na promoção da educação inclusiva no ensino superior. Fernandes e Costa (2015) apresentaram o relato de uma pesquisa que objetivou analisar e descrever a percepção de estudantes com deficiência visual e sem deficiência sobre a atividade de tutoria de pares. Para tanto, foram selecionados sete estudantes com deficiência visual, denominados de tutorados, e seis sem deficiência, na condição de tutores, ambos frequentavam na instituição o Núcleo de Atendimento a Pessoas com Necessidades Específicas (Napne), pertencente a um Instituto Federal de Educação, Ciência e Tecnologia. Foram entrevistados os dois conjuntos de participantes com a intenção de averiguar a relação estabelecida no contexto universitário. A análise de conteúdo foi usada para interpretação dos dados e contou com o auxílio do mapa conceitual elaborado pelo software Atlas.Ti. Os resultados indicaram, por um lado, que os tutores precisam de maiores informações e conhecimentos para atuar na função, por outro, os tutorados "[...] destacam principalmente o papel de auxiliar, adaptar materiais e esclarecer dúvidas, outras definições em minoria são as de ajudar em sala de aula, fornecer suporte e nivelar ('igualar') o acesso ao conhecimento" (FERNANDES; COSTA, 2015, p. 48). Práticas como essa podem atuar como suporte educacional favorecendo a aprendizagem acadêmica de estudantes com deficiência visual.

O estudo de Lima et al. (2016) objetivou debater o tema inclusão no ensino superior a partir da prática profissional de estagiárias em psicologia escolar de uma instituição de ensino superior (IES), localizada em Brasília, pelo intermédio do atendimento realizado a duas graduandas. Os casos em questão foram encaminhados ao estágio pelos respectivos coordenadores de curso em função de dificuldades de aprendizagem apresentadas pelas estudantes. O texto destaca a atuação da psicologia escolar no suporte prestado para o acompanhamento acadêmico individual das estudantes, enfocando as suas reais possibilidades. As autoras relatam que casos como esses fomentaram a implantação de um Serviço de Atendimento às Queixas Escolares (SAQUE) para auxiliar estudantes que apresentem dificuldades na aprendizagem durante a trajetória universitária. $\mathrm{O}$ estudo evidencia a importância da atuação do psicólogo escolar no contexto universitário na promoção da educação inclusiva. No entanto, o estudo realizado ainda se esgota em trabalhar mais com os estudantes e pouco com outros personagens da vida acadêmica. 
Com a intenção de se investigar as ações exercidas pelos Núcleos de Acessibilidade em prol da participação das pessoas com deficiência nas instituições federais de ensino superior (IFES), constituídos com o auxílio do Programa Incluir no ano de 2013, Ciantelli e Leite (2016) realizaram a pesquisa com os coordenadores desses núcleos. Informa-se que a coleta de dados se deu por questionário, encaminhado a eles via formulário eletrônico, pelo recurso do Google Docs. Seu objetivo contemplou em traçar um panorama das ações desenvolvidas pelas universidades em relação aos estudantes com deficiência. As respostas dos 17 coordenadores participantes foram categorizadas nos tópicos temáticos de análise da estrutura física, da estrutura humana e da ajuda técnica, sendo levantadas as condições de acessibilidade nos âmbitos arquitetônicos, comunicacionais, instrumentais, metodológicos e programáticos. Foi constatada a oferta de várias ações, no entanto, ainda são necessárias, nas palavras das autoras, “[...] alterações no regimento interno, no projeto político-pedagógico e no plano de desenvolvimento institucional das instituições de ensino superior brasileira, em prol de uma educação menos excludente" (CIANTELLI; LEITE, 2016, p. 426). Depreende-se que os Núcleos de Acessibilidade têm se configurado como uma nova ação nas IFES em decorrência de ações afirmativas governamentais para atender essa demanda estudantil.

Com a intenção de investigar ações de suporte educacional para estudantes com deficiência, Castro e Almeida (2014) realizaram um amplo estudo que buscou identificar e analisar as condições de acesso dos estudantes com deficiência ao ensino superior. Para o alcance da meta, fizeram uma pesquisa de campo em 13 universidades públicas que apresentavam mais de 20 alunos, com deficiência matriculados, de diferentes regiões do Brasil. A amostra da pesquisa contou com dois grupos de participantes, sendo 12 Coordenadores de Serviço de Apoio especializado aos alunos com deficiência e 30 estudantes com deficiência. Como materiais utilizou-se a análise de documentos, a aplicação de entrevistas, elaboração de diário de campo e adicionalmente o uso de fotografias. Os dados obtidos, com as entrevistas realizadas e com os dois conjuntos de participantes, foram submetidos à análise de conteúdo, sendo classificados em categorias que retratavam as barreiras, facilidades e sugestões quanto à acessibilidade no contexto universitário. Seguiu-se um amplo conjunto de dados, subdividido por instituição de ensino superior investigada e associado à análise dos relatos dos estudantes diante das categorias mencionadas. Tal estudo pode oferecer uma cuidadosa e ampla pesquisa sobre o panorama real da permanência de estudantes com deficiência, matriculados nas universidades públicas do país. 


\section{Mapeamento e trajetória de pessoas com deficiência no ensino superior}

Guarinello et al. (2009) discutem as práticas sociais de leitura e escrita de estudantes universitários surdos. A pesquisa foi realizada com 20 discentes surdos inseridos em diferentes universidades de Curitiba/PR, a partir da aplicação de um questionário para coletar informações sobre as práticas cotidianas de leitura e escrita vivenciadas pelos sujeitos ao entrarem em contato com diferentes gêneros textuais. Os autores mostraram que muitos surdos são considerados iletrados funcionais por não dominarem a língua portuguesa em sua forma escrita. Também que, no contexto brasileiro, apesar dos avanços legais, muitos surdos não tiveram e continuam não tendo acesso à língua de sinais (Libras). Em função disso e das fragilidades apresentadas pela escola brasileira em garantir as condições necessárias para os surdos construírem o seu conhecimento, parte significativa enfrenta dificuldades de letramento e da linguagem escrita, aspecto que continua presente no ensino superior. Segundo os autores, esse fato é decorrente de práticas de ensino da língua escrita por meio de propostas mecânicas, descontextualizada e repetitivas. Os dados da pesquisa evidenciaram a importância da Libras e do intérprete de Libras na trajetória dos sujeitos surdos, participantes da investigação, como garantido pela Lei de Acessibilidade $\mathrm{n}^{\circ}$ 10.098, de 19 de dezembro de 2000. Todavia, os dados sinalizaram que a relação entre o intérprete em sala de aula e a aquisição de conhecimento ou facilidade para a leitura e produção textual não foi direta.

Também discutindo aspectos relacionados à surdez, o artigo de Cruz e Dias (2009) apresenta a trajetória acadêmica de sete discentes surdos no ensino superior a partir de entrevistas individuais realizadas presencialmente e a distância, empregando o português, falado e escrito, ou Libras, com apoio de um intérprete. A análise dos dados tomou como referência os estudos socioantropológicos que entendem os sujeitos surdos como integrantes de uma minoria linguística e culturalmente diferentes.

Os resultados da investigação indicaram as dificuldades enfrentadas pelos sujeitos para participar plenamente das atividades acadêmicas. Mostraram que, como em períodos anteriores - como da integração, os surdos eram obrigados a superar suas especificidades buscando individualmente recursos para isso. Os relatos dos entrevistados, por exemplo, indicaram que as proposições de ensino, oferecidas nos cursos frequentados pelos surdos, seguiam ainda propostas como o oralismo e a comunicação total. Isso foi constatado em função da organização dos cursos e das aulas que focalizavam propostas de ensino somente para ouvintes 
e a ausência de intérprete em sala de aula, dificultando a ação dos professores diante da presença de um estudante surdo.

Novamente a compreensão e a vivência universitária de cinco estudantes surdos, que frequentaram escolas bilíngues e se identificam com a cultura surda, foram temas do artigo de Bisol et al. (2010). Para a coleta de dados, as autoras realizaram entrevistas semiestruturadas, gravadas em vídeo, depois transcritas para o português, sendo submetidas à análise de conteúdo. Os resultados da pesquisa mostraram, assim como nos estudos de Guarinello et al. (2009) e Cruz e Dias (2009), as dificuldades enfrentadas pelos surdos para terem garantido o seu direito de plena participação nas atividades acadêmicas. Igualmente, o estudo sinalizou para a importância da participação do intérprete da língua de sinais nas aulas, assim como a sua capacitação de acordo com as especificidades dos cursos de graduação. Outro aspecto revelado e constante nos estudos, envolvendo a inclusão de pessoas surdas no ensino superior, diz respeito à transição entre a língua de sinais e à língua portuguesa, o que, para os sujeitos participantes, incidiu diretamente na realização das tarefas envolvendo leitura e escrita.

As autoras concluem que a inclusão de estudantes surdos no ensino superior acaba provocando uma "desestabilização de estruturas cristalizadas" e "não apenas o professor, mas também os alunos ouvintes precisam rever o modo de organizar e de conduzir as interações em sala de aula para que os colegas surdos possam se beneficiar dos recursos disponíveis" (BISOL et al., 2010, p. 164-165). Dessa forma, contribuindo para que novas possibilidades e relações sejam estabelecidas para garantir a inclusão da diversidade no contexto do ensino superior contemporâneo.

Como relatado em outro artigo, citado neste estudo, a pesquisa retratada por Duarte et al. (2013) buscou traçar um panorama sobre as matrículas de estudantes com deficiência no ensino superior, após a implantação de políticas governamentais que promovem o acesso dessa população a níveis mais elevados de ensino, tendo como destaque o ProUni, o REUNI e o FIES. Os autores partem da revisão do processo de inclusão/exclusão enfrentados pelas pessoas com deficiência no seu processo de escolarização. Na tentativa de retratar a realidade do município de Juiz de Fora/MG, entrevistaram 21 coordenadores de oito instituições de ensino superior (IES) de natureza privada e 35 coordenadores dos cursos da única universidade pública no sítio investigado. Como grande parte dos estudos retratados neste texto, a entrevista foi a forma utilizada para a coleta dos dados. Os autores anunciaram sinteticamente alguns achados, como, em 2009, 45 alunos com deficiência matriculados estavam nas IES investigadas, sendo que a maior parte, ou seja, 27 nas IES privadas, e a maioria destes em cursos noturnos. Atribuem, como um dos motivos, que essa diferença se dê ao processo seletivo ser menos competitivo nas instituições particulares. Ainda 
retrataram que a deficiência física seguida da auditiva eram mais presentes entre os estudantes mapeados.

Diferentemente dos demais estudos que se debruçaram sobre a deficiência, a pesquisa realizada por Cianca e Marquezine (2014) se direcionou a investigar estudantes com altas habilidades/superdotação (AH/SD) que frequentam o ensino superior. Tal escolha é interessante, visto que muitos se esquecem de que essa demanda também faz parte do público-alvo da Educação Especial. Nesse direcionamento as autoras analisaram a percepção de 14 coordenadores de cursos de licenciatura de uma universidade estadual do Paraná pelo intermédio da aplicação de entrevistas individuais. Como em outros estudos aqui citados, a análise de conteúdo foi utilizada na interpretação dos dados, sendo elencadas dez classes para analisar a compreensão dos participantes em relação à AS/DT. Nas conclusões destaca-se o relato das autoras referente à percepção geral das falas dos docentes participantes, a qual indica que "[...] estava diretamente ligada ao conhecimento trazido pelo senso comum e não condizia com o conhecimento científico da área. A ideia de o superdotado ser alguém muito diferente, ou somente presente nas histórias de ficção, o deixa muito distante do real" (CIANCA; MARQUEZINE, 2014, p. 602). Terminam reconhecendo os limites da investigação, mas enfatizando igualmente que percepções como essas podem auxiliar novos professores a reproduzirem discursos que auxiliam na manutenção de mitos que envolvam pessoas com as AH/SD, uma vez que se investigou docentes que atuam em cursos de licenciatura.

Calheiros e Fumes (2016) pesquisaram o processo de inclusão de universitários com deficiência em cursos de graduação em Educação Física da cidade de Maceió/AL. Partiram de uma abordagem qualitativa atrelada ao método de estudo de caso com a aplicação de entrevista semiestruturada. Após levantamento junto às instituições de ensino superior (IES) que ofertassem o curso de Educação Física no município citado e que tivessem matrículas de estudantes com deficiência, os autores chegaram ao número de cinco participantes. Esses estavam matriculados em duas IES de natureza privada. A amostra contou com quatro estudantes com surdez e um com deficiência física, além de dois coordenadores de curso. $\mathrm{Na}$ análise das entrevistas, pela técnica análise de conteúdo, foi possível notar um descompasso entre o discurso dos coordenadores com o dos estudantes participantes, pois enquanto os primeiros relatavam a oferta de condições e recursos específicos, os estudantes apontavam que a permanência no ensino superior estava condicionada mais ao esforço pessoal atrelado ao auxílio dos colegas da turma, situações identificadas como favorecedoras para que pudessem acompanhar as atividades acadêmicas, ao invés de ajustes e/ou provimentos institucionais. O estudo concluiu que a "[...] participação desse público na educação superior estava ainda muito condicionada às suas capacidades de adaptação a ambientes não inclusivos" (CALHEIROS; FUMES, 2016, p. 536). 


\section{Considerações finais}

Com o objetivo de evidenciar um estado da arte da produção científica envolvendo a temática inclusão no ensino superior, apresentamos ao longo deste artigo a análise da produção científica publicada na base de dados Scientific Eletronic Library Online (SciELO -BRASIL), no ínterim 2008-2016.

Nossas análises puderam identificar um avanço na produção científica, sobretudo, envolvendo a participação de pessoas surdas e cegas no ensino superior, assim como os desafios e caminhos encontrados pelas universidades para garantir a plena participação desses sujeitos nas atividades acadêmicas.

Também verificamos que as práticas e as concepções docentes sobre a temática têm sido positivas para atender a essa nova demanda educacional. No entanto, o corpo de pesquisadores, de um modo geral, aponta a necessidade de conteúdos que versem sobre o ensino e as atitudes dirigidas às pessoas com deficiência, tanto nos cursos de formação inicial como nas proposições de formação continuada, favorecendo subsídios teórico-operacionais para a experiência profissional. Foi igualmente notado a necessidade da remoção das barreiras arquitetônicas, da oferta de material didático para as aulas com pessoas com deficiência visual e a presença do intérprete de Libras para surdos, por exemplo.

Por fim, em termos gerais, podemos concluir que, apesar do avanço na produção de conhecimento sobre o tema, este ainda está muito aquém da demanda estudantil que cresce de forma acelerada como apontado no início deste artigo. A evolução da matrícula de estudantes classificados como público-alvo da Educação Especial tem se dado, em grande medida, pelo incremento de políticas públicas que fomentam o acesso desses sujeitos a níveis mais elevados de ensino. Tal aspecto coloca para as universidades o enfrentamento de uma série de questões para além das de infraestrutura, como de ordem pedagógica, social e atitudinal.

\section{REFERÊNCIAS}

BRASIL. Política Nacional de Educação Especial na Perspectiva da Educação Inclusiva. Brasília, jan. 2008.

BRASIL. Convenção sobre os Direitos das Pessoas com Deficiência (2007). 4. ed., rev. e atual. Brasília: Secretaria de Direitos Humanos, Secretaria Nacional de Promoção 
dos Direitos da Pessoa com Deficiência, 2011. Disponível em: <http://www.pessoacomdeficiencia.gov.br/app/publicacoes/convencao-sobre-os-direitos-das-pessoas-com-deficiencia>. Acesso em: 10 ago. 2016.

BRASIL, Secretaria de Direitos Humanos da Presidência da República (SDH/PR), Secretaria Nacional de Promoção dos Direitos da Pessoa com Deficiência (SNPD), Coordenação-Geral do Sistema de Informações sobre a Pessoa com Deficiência. Cartilha do Censo 2010 - Pessoas com Deficiência. Equipe Técnica: Luiza Maria Borges Oliveira. Brasília: SDH-PR/SNPD, 2012.

BISOL, C. A.; VALENTINI, C. B.; SIMIONI, J. L.; ZANCHIN, J. Estudantes surdos no ensino superior: reflexões sobre a inclusão. Cadernos de Pesquisa, v. 40, n. 139, p. 147-172, 2010. Disponível em: <http://www.scielo.br/scielo.php?pid=S0100$-15742010000100008 \&$ script=sci_abstract\&tlng=pt $>$. Acesso em: 10 ago. 2016.

CASTRO, S. F. de; ALMEIDA, M. A. Ingresso e permanência de alunos com deficiência em universidades públicas brasileiras. Rev. Bras. Educ. Espec., Marília, v. 20, n. 2, p. 179-194, jun. 2014. Disponível em $<$ http://www.scielo.br/scielo.php?script=sci arttext\&pid=S1413-65382014000200003\&lng=en\&nrm=iso $>$. Acesso em: 7 set. 2016.

CALHEIROS, D. S.; FUMES, N. L. F. A inclusão de universitários com deficiência em cursos de Educação Física na cidade de Maceió/AL. Avaliação (Campinas), Sorocaba, v. 21, n. 2, p. 523-540, jul. 2016. Disponível em <http://www.scielo.br/scielo. php?script $=$ sci_arttext\&pid $=$ S1414-40772016000200523\&lng $=$ pt\&nrm $=$ iso $>$. Acesso em: 31 ago. $20 \overline{1} 6$.

CIANCA, F. S. C.; MARQUEZINE, M. C. A percepção dos coordenadores de licenciaturas da UEL sobre altas habilidades/superdotação. Rev. bras. educ. espec., Marília, v. 20, n. 4, p. 591-604, dez. 2014. Disponível em: $<$ http://www.scielo.br/scielo.php?script=sci arttext\&pid=S1413-65382014000400010\&lng=en\&nrm=iso >. Acesso em: 7 set. 2016.

CIANTELLI, A. P. C.; LEITE, L. P. Ações Exercidas pelos Núcleos de Acessibilidade nas Universidades Federais Brasileiras. Rev. Bras. Educ. Espec., Marília, v. 22, n. 3, p. 413-428, set. 2016. Disponível em: <http://www.scielo.br/scielo.php?script=sci arttext\&pid=S1413-65382016000300413\&lng=pt\&nrm=iso $>$. Acesso em: 31 ago. 2016.

CRUZ, J. I. G. da; DIAS, T. R. da S. Trajetória escolar do surdo no ensino superior: condições e possibilidades. Rev. Bras. Educ. Espec., v. 15, n. 1, p. 65-80, 2009. Disponível em: <http://www.scielo.br/scielo.php?pid=S1413-65382009000100006\&script=sci abstract\&tlng=pt>. Acesso em: 10 ago. 2016.

DUARTE, E. R.; RAFAEL, C. B. S.; FILGUEIRAS, J. F.; NEVES, C. M.; FERREIRA, M. E. C. Estudo de caso sobre a inclusão de alunos com deficiência no ensino superior. Rev. Bras. Educ. Espec., Marília, v. 19, n. 2, p. 289-300, jun. 2013. Disponível em: <http:// www.scielo.br/scielo.php?script=sci_arttext\&pid=S1413-65382013000200011\&lng=en $\& n r m=$ iso $>$. Acesso em: 7 set. 2016. 
FERREIRA, N. S. A. As pesquisas denominadas “estado da arte". Educ. Soc.[online], v. 23, n. 79, p. 257-272, 2002. Disponível em: $<$ http://www.scielo.br/scielo.php?pid=S0101$-73302002000300013 \&$ script=sci_abstract\&tlng=pt>. Acesso em: 10 ago. 2016.

FERNANDES, W. L.; COSTA, C. S. L. possibilidades da tutoria de pares para estudantes com deficiência visual no ensino técnico e superior. Rev. Bras. Educ. Espec., Marília, v. 21, n. 1, p. 39-56, mar. 2015. Disponível em: <http://www.scielo.br/scielo. php?script $=$ sci_arttext\&pid=S1413-65382015000100039\&lng=en\&nrm=iso $>$. Acesso em: 7 set. 2016 .

FRANCO, M. Educação superior bilíngue para surdos: o sentido da política inclusiva como espaço da liberdade: primeiras aproximações. Rev. Bras. Educ. Espec., v. 15, n. 1, p. 15-30, jan./abr. 2009. Disponível em: $<$ http://www.scielo.br/scielo.php?script=sci arttext\&pid=S1413-65382009000100003\&lng=en\&nrm=iso\&tlng=pt $>$. Acesso em: 10 ago. 2016.

GUARINELLO, A. C. et al. Surdez e letramento: pesquisa com surdos universitários de Curitiba e Florianópolis. Rev. Bras. Educ. Espec., v. 15, n. 1, p. 99-120, jan./abr. 2009. Disponível em: <http://www.scielo.br/scielo.php?pid=S1413-65382009000100008\&script=sci abstract\&tlng=pt $>$. Acesso em: 10 ago. de 2016.

INEP. Microdados sobre matrículas. Disponível em: <http://portal.inep.gov.br/>. Acesso em: 10 ago. 2016.

IBGE. Censo 2010. Disponível em: <http://censo2010.ibge.gov.br/>. Acesso em: 10 ago. 2016.

LACERDA, C. B. F.; GURGEL, T. M. A. Perfil de tradutores-intérpretes de Libras (TILS) que atuam no ensino superior no Brasil. Rev. Bras. Educ. Espec. [online], v. 17, n. 3, p. 481-496, set./dez. 2011. Disponível em: <http:/www.scielo.br/pdf/rbee/v17n3/ v17n3a09.pdf>. Acesso em: 10 ago. 2016.

LIMA, A.; MARQUES, A. P. S.; LIMA, A. H. S.; LOBATO, G. C. Inclusão no ensino superior: uma proposta de ação em Psicologia Escolar. Psicol. Esc. Educ., Maringá, v. 20, n. 1, p. 175-177, abr. 2016. Disponível em $<$ http://www.scielo.br/scielo.php?script=sci arttext\&pid=S1413-85572016000100175\&lng=en\&nrm=iso $>$. Acesso em: 31 ago. 2016.

MARTINS, D. A.; LEITE, L. P.; BROGLIA, C. Políticas públicas para acesso de pessoas com deficiência ao ensino superior brasileiro: uma análise de indicadores educacionais. Revista Ensaio: Avaliação e Políticas Públicas em Educação, [s. 1.], v. 23, n. 89, p. 9841014, nov. 2015. Disponível em: < http://revistas.cesgranrio.org.br/index.php/ensaio/ article/view/772>. Acesso em: 7 set. 2016.

MOREIRA, L. C.; BOLSANELLO, M. A.; SEGER, R. G. Ingresso e permanência na Universidade: alunos com deficiências em foco. Educ. rev. [online], n. 41, p. 125 143, 2011. Disponível em: <http://www.scielo.br/scielo.php?script=sci_arttext\&pid =S0104-40602011000300009>. Acesso em: 10 ago. 2016 . 
NASCIMENTO, F. F.; CRUZ, M. M.; BRAUN, P. Escolarização de Pessoas com Transtorno do Espectro do Autismo a Partir da Análise da Produção Científica disponível na SciELO Brasil (2005-2015). Arquivos Analíticos de Políticas Educativas, v. 24, n. 125, dez. 2016.

OLIVEIRA, R. Q. et al. A inclusão de pessoas com necessidades especiais no ensino superior. Rev. Bras. Educ. Espec., Marília, v. 22, n. 2, p. 299-314, jun. 2016. Disponível em: <http://www.scielo.br/scielo.php?script=sci_arttext\&pid=S1413$-65382016000200299 \& \operatorname{lng}=\mathrm{en} \& n r m=\mathrm{iso}>$. Acesso em: 31 ago. 2016.

PEREIRA, F. J. R.; SANTOS, S. R.; SILVA, C. C. Política de formação inclusiva: percepção de gestores sobre processo de mudanças em instituições de ensino superior. Rev. Bras. Enferm., v. 64, n. 4, p. 711-716, 2011. Disponível em: <http://www.scielo. br/scielo.php?pid=S0034-71672011000400013\&script $=$ sci_abstract\&tlng=pt $>$. Acesso em: 10 ago. 2016.

REIS, M. X.; EUFRÁSIO, D. A.; BAZON, F. V. M. A formação do professor para o ensino superior: prática docente com alunos com deficiência visual. Educ. Rev. [online], v. 26, n. 1, p. 111-130, 2010. Disponível em: $<$ http://www.scielo.br/scielo.php?script=sci_art text\&pid=S0102-46982010000100006>. Acesso em: 10 ago. 2016.

SANTOS, E.; GONÇALVES, M.; RAMOS, I.; CASTRO, L.; LOMEO, R. Inclusão no ensino superior: percepções dos estudantes com necessidades educativas especiais sobre o ingresso à universidade. Revista Portuguesa de Educação, v. 28, n. 2, p. 251-270, 2015.

SIQUEIRA, I. M.; SANTANA, C. S. Propostas de acessibilidade para a inclusão de pessoas com deficiências no ensino superior. Rev. bras. educ. espec. [online], v. 16, n. 1, p. 127-136, 2010. Disponível em: <http://www.scielo.br/scielo.php?script=sci_artte xt\&pid=S1413-65382010000100010>. Acesso em: 10 ago. 2016.

SILVA, A. M.; CYMROT, R.; D’ANTINO, M. E. F. Demandas de docentes do ensino superior para a formação de alunos com deficiência. Rev. Bras. Estud. Pedagog. [online], v. 93, n. 235, p. 667-697, 2012. Disponível em: <http://rbep.inep.gov.br/index.php/rbep/ article/view/411/0>. Acesso em: 10 ago. 2016.

Texto recebido em 31 de maio de 2017. Texto aprovado em 10 de junho de 2017. 